\title{
Flow Boiling Characteristics of R245fa in a Plate and Shell Heat Exchanger
}

\author{
Kang Sub Song ${ }^{1}$, Junyub Lim ${ }^{1}$, Sungho Yun ${ }^{1}$, Junho Kwon ${ }^{1}$, Yongchan Kim ${ }^{2}$ \\ ${ }^{1}$ Graduate School of Mechanical Engineering, Korea University \\ 145 Anam-Ro, Seongbuk-Gu, Seoul, Republic of Korea \\ alwayswin@korea.ac.kr; diglim@korea.ac.kr; hadogo@korea.ac.kr; junho85930@korea.ac.kr \\ ${ }^{2}$ Department of Mechanical Engineering, Korea University \\ 145 Anam-Ro, Seongbuk-Gu, Seoul, Republic of Korea \\ yongckim@korea.ac.kr
}

\section{Extended Abstract}

Recently, environmental and energy regulations are being strengthened all over the world. In this environment, various studies have being conducted to utilize the high-temperature waste heat abandoned in industrial fields. Therefore, the selection of a heat exchanger suitable for high-temperature applications is essential. A plate and shell heat exchanger (PSHE) is a heat exchanger that combines the advantages of a shell and tube heat exchanger and a plate heat exchanger. It is suitable for use in such high-temperature conditions and has high thermal efficiency.

Previous studies investigated the flow boiling heat transfer and pressure drop characteristics of various refrigerants $[1,2]$. However, these studies have mainly been conducted under low-temperature conditions, and few studies have been conducted in PSHEs. Therefore, in this study, the flow boiling heat transfer and pressure drop characteristics of R245fa with high critical temperature were studied in PSHEs at relatively high-temperature conditions of $60-80^{\circ} \mathrm{C}$. The channels in the heat exchanger were composed of counter flow. The upward flow of R245fa received heat from the downward flowing water. The heat transfer plates had a $50^{\circ}$ chevron. In addition to the saturation temperature, the experiments were performed by varying mean vapor quality, mass flux, and heat flux. The water to water experiments were carried out before the flow boiling experiment. The water side correlation was developed using the modified Wilson plot method [3].

As the saturation temperature increased, the heat transfer coefficient increased and frictional pressure drop decreased due to decreased specific volume of vapor. As the mean vapor quality increased, the heat transfer coefficient and frictional pressure drop increased due to increased velocity of vapor. However, the heat transfer coefficient decreased after a certain value due to dry-out. As the mass flux increased, the heat transfer coefficient and frictional pressure drop increased due to the increased velocity and turbulence. The effects of the heat flux on heat transfer coefficient and frictional pressure drop were not significant. The variations of the heat transfer and pressure drop with variables were more sensitive to vapor state than liquid state. The correlations on the heat transfer and pressure drop of R245fa in PSHE were developed in terms of equivalent Reynolds number and Prandtl number.

\section{Acknowledgement}

This work was supported by the Industrial Core Technology Development Program (No. 10049090) of the Korea Evaluation Institute of Industrial Technology (KEIT) funded by the Korea Government Ministry of Trade, Industry, and Energy.

\section{References}

[1] Y. Y. Hsieh and T. F. Lin, "Evaporation Heat Transfer and Pressure Drop of Refrigerant R-410A Flow in a Vertical Plate Heat Exchanger," J. Heat Transfer., vol. 125, no. 5, pp. 852-857, 2003.

[2] G. A. Longo and A. Gasparella, "Heat transfer and pressure drop during HFC refrigerant vaporisation inside a brazed plate heat exchanger," Int. J. Heat Mass Transf., vol. 50, no. 25-26, pp. 5194-5203, 2007.

[3] E. E. Wilson, "A basis for rational design of heat transfer apparatus," ASME J. Heat Transf., vol. 37, pp. 47-70, 1915. 